\title{
Dietary intervention with a specific micronutrient combination for the treatment of patients with cardiac arrhythmias: the impact on insulin resistance and left ventricular function
}

\author{
Elke Parsi ${ }^{1 *}$ D, Norman Bitterlich², Anne Winkelmann ${ }^{1}$, Daniela Rösler ${ }^{3}$ and Christine Metzner ${ }^{3,4}$
}

\begin{abstract}
Background: Cardiac arrhythmias (CA) are very common and may occur with or without heart disease. Causes of these disturbances can be components of the metabolic syndrome (MetS) or deficits of micronutrients especially magnesium, potassium, B vitamins and coenzyme Q10. Both causes may also influence each other. Insulin resistance (IR) is a risk factor for diastolic dysfunction. One exploratory outcome of the present pilot study was to assess the impact of a dietary intervention with specific micronutrients on the lowering of IR levels in patients with CA with the goal to improve the left ventricular (LV) function.

Methods: This was a post hoc analysis of the randomized double blind, placebo-controlled pilot study in patients with CA (VPBs, SVPBs, SV tachycardia), which were recruited using data from patients who were 18-75 years of age in an Outpatient Practice of Cardiology. These arrhythmias were assessed by Holter ECG and LV function by standard echocardiography. Glucose metabolism was measured by fasting glucose, fasting insulin level and the Homeostasis Model Assessment of IR (HOMA-IR) at baseline and after 6 weeks of dietary supplementation.

Results: A total of 54 randomized patients with CA received either a specific micronutrient combination or placebo. Dietary intervention led to a significant decrease in fasting insulin $\geq 58 \mathrm{pmol} / \mathrm{I}(p=0.020)$, and $\operatorname{HOMA-IR}(p=0.053)$ in the verum group after 6 weeks. At the same time, parameters of $L V$ diastolic function were improved after intervention in the verum group: significant reduction of LV mass index $(p=0.003)$, and in tendency both a decrease of interventricular septal thickness $(p=0.053)$ as well as an increase of E/A ratio $(p=0.051)$. On the other hand, the premature beats (PBs) were unchanged under verum.
\end{abstract}

Conclusions: In this pilot study, dietary intervention with specific micronutrient combination as add-on to concomitant cardiovascular drug treatment seems to improve cardio metabolic health in patients with CA. Further studies are required.

Study registration: The study was approved by the Freiburg Ethics Commission International and was retrospectively registered with the U.S. National Institutes of Health Clinical Trials gov ID NCT 02652338 on 16 December 2015.

Keywords: Diastolic LV function, LVMI, Dietary intervention, Glucose metabolism, Premature beats

\footnotetext{
* Correspondence: praxisparsi@t-online.de

'Outpatient Practice of Cardiology, Suermondtstr. 13, D-13053 Berlin,

Germany

Full list of author information is available at the end of the article
}

(c) The Author(s). 2018 Open Access This article is distributed under the terms of the Creative Commons Attribution 4.0 International License (http://creativecommons.org/licenses/by/4.0/), which permits unrestricted use, distribution, and reproduction in any medium, provided you give appropriate credit to the original author(s) and the source, provide a link to the Creative Commons license, and indicate if changes were made. The Creative Commons Public Domain Dedication waiver (http://creativecommons.org/publicdomain/zero/1.0/) applies to the data made available in this article, unless otherwise stated. 


\section{Background}

Supraventricular (SVPBs) and ventricular premature beats (VPBs) are very common arrhythmias in patients with cardiovascular disorders. The incidence of SVPBs in Electrocardiogram (ECG) at rest is present in 10-20\% [1], VPBs in $5-10 \%$ [2]. The prevalence is increasing with age. Patients with components of MetS like arterial hypertension $(\mathrm{AH})$, abdominal obesity, type 2 diabetes mellitus (T2DM), impaired glucose tolerance (IGT) or HOMA-IR also show in addition to CA in different degree disturbances in cardiac metabolism and LV function. Based on abdominal obesity, IGT driven by IR leads already at an early stage to changes of diastolic function in different degree $[3,4]$. The diastolic dysfunction is described with different parameters $[5,6]$ but according to the current ESC Guidelines for the diagnosis and treatment of acute and chronic heart failure, one of important parameter to describe the diastolic function is the left ventricular mass index (LVMI) [7].

Numerous studies on therapeutic interventions with magnesium [8-12], potassium [13], B vitamins [14-19], and Coenzyme Q10 [20-24] for CA and cardiometabolic risk factors have been published. An insufficient supply of magnesium can be clinical relevant as a trigger of CA and can also be linked with different components of the MetS like T2DM, and insulin resistance as well as by therapy with proton-pump inhibitors [25] and diuretics [12]. It may be caused by poor oral intake, elevated renal loss, diarrhea or alcoholism. The hypomagnesemia is also often combined with hypokalemia [26].

One objective of this pilot study was to investigate, if daily dietary intervention with a specific micronutrient combination improved LV function of CA in patients with disturbances in glucose metabolism after 6 weeks.

\section{Methods}

\section{Study population}

This was a post hoc analysis of the randomized double blind, placebo-controlled pilot study in patients with CA, which were recruited from patients who were 1875 years of age in an Outpatient Practice of Cardiology in Berlin, Germany. 74 Caucasian patients with cardiac arrhythmias (VPBs, SVPBs, SV tachycardia) were screened from April 2014 to July 2015. Overall, patients who completed the study participated in 5 visits in the Outpatient Practice of Cardiology. At the first visit the patients were informed about the study in detail and the necessary examinations for inclusion and exclusion criteria were carried out. If the criteria were met and the patient gave his written consent to participate in the study, the placebo tablets for the run-in phase were issued at the second visit. Visit 3 marked the time baseline, again the inclusion and exclusion criteria were examined and the patients randomized. A further visit followed after a 3-week intervention phase, before 6 weeks follow-up.

Inclusion criteria were: $\geq 500$ VPBs or $\geq 200$ SVPBs or $\geq 10 \mathrm{SV}$ tachycardia's in Holter ECG at least $18 \mathrm{~h}$. The general exclusion criteria were age $>75$ years, LVEF $\leq 40 \%$, intake of spironolactone $>50 \mathrm{mg} / \mathrm{d}$, torasemide $>$ $20 \mathrm{mg} / \mathrm{d}$, supplementation of vitamins and minerals, hypo- or hyperkalemia, hypo- or hypermagnesemia, impaired renal function, hyperthyreosis, cardiac pacemaker, acute or chronic diarrhoea. Fourteen screened patients don't meet the inclusion criteria: They have not had the amount of supraventricular or ventricular ectopic beats, and one patient had a hypomagnesemia.

Figure 1 shows the trial profile of the 74 screened patients. All included subjects received placebo administration (2 tablets 2 times a day) during a one-week run-in period. After evaluation of the Holter ECG at baseline and check of the inclusion criteria 60 patients were randomly assigned to the verum or placebo group. Duration of dietary intervention was 6 weeks. Over this period of the randomized double blind, placebo-controlled pilot study, participants were required to take 2 tablets 2 times a day of verum (5 kcal, $145.8 \mathrm{mg}$ magnesium, $469.2 \mathrm{mg}$ potassium, 3.0 $\mu \mathrm{g}$ Vitamin B12, $400.0 \mu \mathrm{g}$ folic acid, $48.0 \mathrm{mg}$ niacin and $60.0 \mathrm{mg}$ coenzyme Q10) or placebo (microcrystalline cellulose) with $200 \mathrm{ml}$ water.

\section{Outcomes for glucose metabolism and LV function}

The exploratory outcomes were the changes in HOMA-IR and LV function after 6 weeks of dietary intervention in patients with CA.

\section{Clinical measurements of components of the metabolic syndrome}

At baseline the waist circumference (WC) was determined with a flexible tape with a measuring deviation nearest to $0.5 \mathrm{~cm}$. WC was measured at the level midway between the lower rib margin and the iliac crest after breathing out normally and in standing position. MetS was determined by using diagnostic criteria of the International Diabetes Federation (IDF) [27]. The IDF definition requires increased WC, namely $\geq 94 \mathrm{~cm}$ and $\geq 80 \mathrm{~cm}$ for European males and females respectively, and any two of the following four components: systolic blood pressure (BP) $\geq 130$ $\mathrm{mmHg}$ or diastolic $\mathrm{BP} \geq 85 \mathrm{mmHg}$ or treatment of hypertension, triglycerides (TG) $\geq 1.7 \mathrm{mmol} / \mathrm{l}$, HDL-cholesterol $(\mathrm{HDL}-\mathrm{C})<1.29 \mathrm{mmol} / \mathrm{l}$ in females, and $<1.03 \mathrm{mmol} / \mathrm{l}$ in males or treatment for lipid abnormality, fasting glucose $\geq 5.6 \mathrm{mmol} / \mathrm{l}$ or previously diagnosed T2DM. WC and Waist-to-Height-Ratio (WHtR) $>0.5$ are proxy measures of abdominal obesity [28, 29].

In addition, an echocardiography (GE Medical Systems, Vivid S6), as well as a standard 12-leads ECG at rest (EINTHOVEN, GOLDBERGER, WILSON leads) 


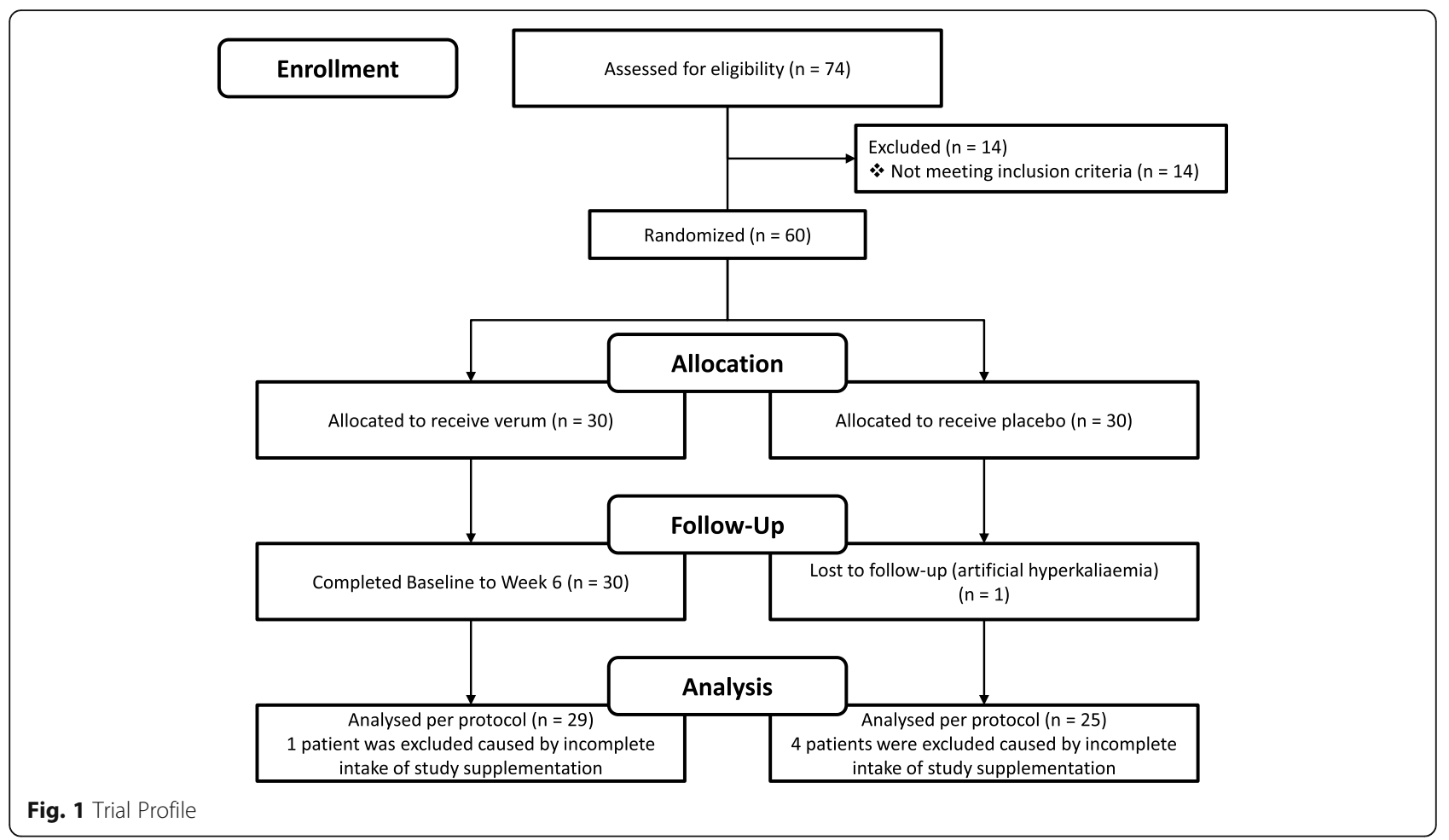

was performed and recorded on CUSTO CARD (custo med $\mathrm{GmbH}$, Munich) as well as a Holter ECG (CUSTO FLASH 500 Multiday, custo med GmbH, Munich) for at least $18 \mathrm{~h}$. ECG at rest and Holter ECG were analysed computer-assisted using Minnesota ECG Code Classification [30]. The SVPBs and VPBs were detected by software and confirmed by 2 cardiologists.

Echocardiographic studies were performed by 2 cardiologists in standard views [31]: parasternal long-axis view of the left ventricle in $2 \mathrm{D}$, colour Doppler and M-mode, parasternal RV inflow- and outflow tract view in 2D and coulour Doppler, apical four- and five chamber view in 2D and colour Doppler, apical two-chamber view in $2 \mathrm{D}$ and colour Doppler, apical long-axis view in 2D and colour doppler, transmitral, transaortic and tricuspid velocities as well as tissue Doppler on mitral annulus (lateral velocities) in 4-chamber-view in accordence to the recommendations [32]. The upper cut off for LVMI in men is $\geq 115 \mathrm{~g} / \mathrm{m}^{2}$ and women $\geq 95 \mathrm{~g} / \mathrm{m}^{2}$ [7]. All echo parameters including LVMI were created by Vivid 6, GE Medical Systems, Ver. 11.2.0 b. 40.

Blood and urinary samples for biochemical assessment were collected at baseline, after 3 and after 6 weeks of dietary intervention (Fig. 2).

\section{Laboratory tests}

All laboratory analyses were conducted by Laboratory Schottdorf MVZ GmbH, Augsburg, Germany. The Analyses of serum glucose (hexokinase method), gammaglutamyltransferase (IFCC method), glycated haemoglobin (HbA1c) (turbidimetric immunologic inhibition assay (TINIA)), insulin (ECLIA), total cholesterol (TC) (CHOD-PAP method), LDL-C and HDL-C (enzymatic colour test), TG (GPO-PAP method) and CRP sensitive (turbidimetry) were performed on a Roche analyser. $24 \mathrm{~h}$ urinary magnesium and potassium excretion was analysed by atomic absorption spectrometry. The HOMA is a measure for IR. HOMA-IR was calculated from insulin and glucose concentrations.

\section{Statistical analysis}

Statistical comparisons were made between groups using the nonparametric Mann-Whitney-U-test. The nonparametric Wilcoxon test was used for data comparison at different time points within groups. Differences in classified variables were tested by Fisher's exact test. The influence of covariates was analysed by analysis of variance (ANOVA). All statistical tests were based on per protocol population and two-sided. Differences were considered significant at $p<0.05$. Data are reported as mean \pm standard deviation (SD). Linear regression modelling was performed to detect the changes of different components of the cardiometabolic parameters as a function of LVMI and serum magnesium concentration. The effect size Cohen's d is defined as the difference between two means divided by a SD for the data. Effect size (ES) threshold: small 0.20 , medium 0.50 , large 0.80 , very large 1.30 [33]. The first and third quartile $(\mathrm{Q} 1$ and Q3 


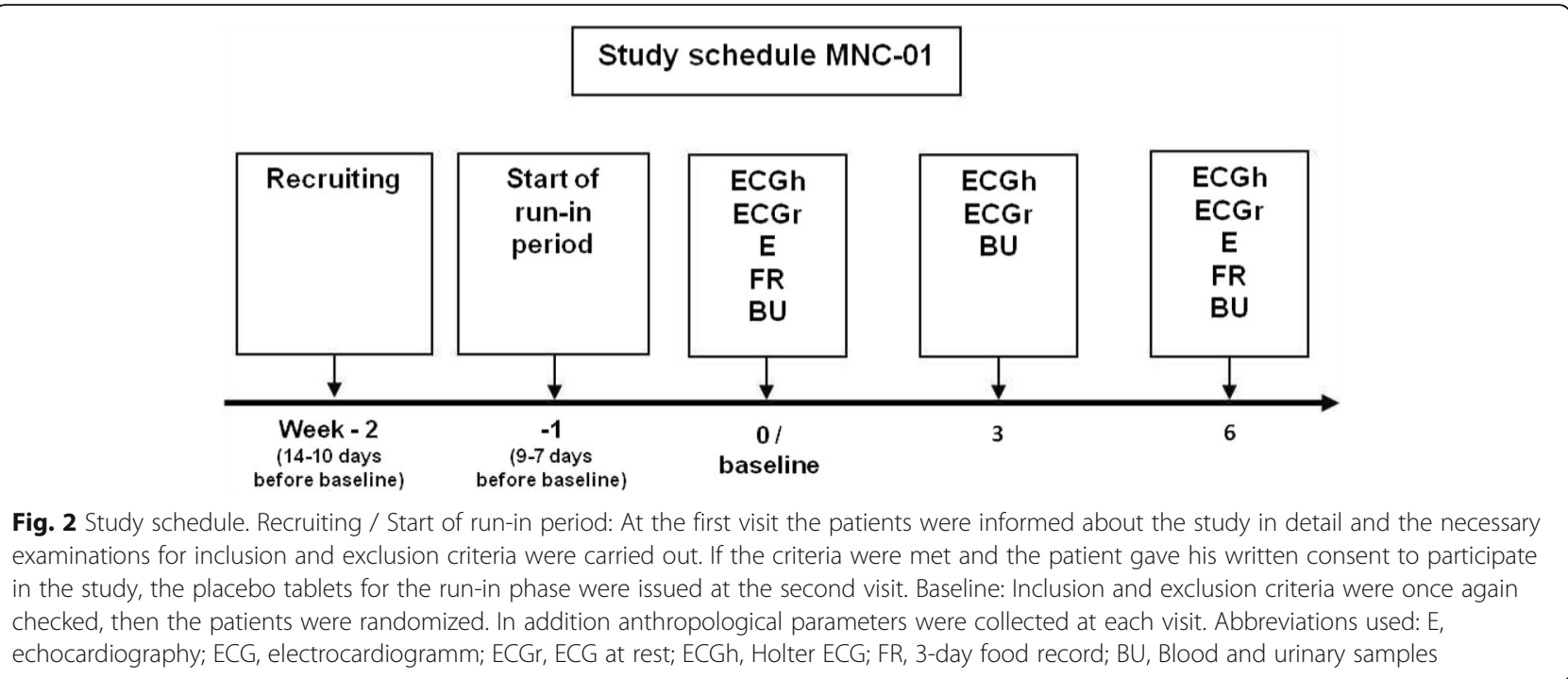

respectively) are shown. All analyses were conducted using SPSS ${ }^{\circ}$ for Windows (version 22.0).

\section{Results}

\section{Patients' characteristics}

Fifty-four patients were evaluated per protocol, 29 in verum group, and 25 in placebo group (Fig. 1). Six patients did not finish the study per protocol: One patient in the placebo group has had an artificial hyperkalemia. 5 patients of the study population consumed less than $95 \%$ of study administration (8\%), 4 of these patients were in placebo group.

No serious side effects were reported under dietary intervention. One patient in the verum group and one in the placebo group reported gastric pain. This could be caused by supplement intake. The supplementation has not been interrupted.

\section{Pre-existing diseases und medications}

Arterial hypertension (AH) was the most frequent pre-existing disease (65.5\% verum group, $52.0 \%$ placebo group). Coronary artery disease (CAD) was present in $27.6 \%$ of patients in the verum group, and in $28.0 \%$ in the placebo group. A long-term medical treatment with beta blocking agents, ACE-inhibitors/AT II receptor antagonists, calcium channel blocker as well as spironolactone was given to 21 patients $(72.4 \%)$ in the verum group and 16 patients $(64.0 \%)$ in the placebo group. T2DM was found in $10.3 \%$ of patients in the verum group and $8.0 \%$ in the placebo group. At baseline $68.5 \%$ of patients had a dyslipidemia (verum $68.9 \%$, placebo $68.0 \%$ ). Treatment with statins was recorded in $34.5 \%$ in the verum group and $28.0 \%$ in the placebo group. Further baseline characteristics of both groups are shown in Table 1.

\section{Metabolic syndrome and its components}

Body mass index $(\mathrm{BMI}) \geq 25 \mathrm{~kg} / \mathrm{m}^{2}$ was recorded in $65.5 \%$ of the verum group and in $72.0 \%$ of the placebo group at baseline. An abdominal obesity with WHtR $\geq 0.5$ was found in $72.4 \%$ of the verum group and in $80.0 \%$ of the placebo group (Table 1). The number of patients with criteria of MetS according to IDF compared to baseline to the study end decreased in the verum group of 16 to 15 , and on the contrary in the placebo group increased from 8 to 12 . At baseline 5 patients $(17.2 \%)$ in the verum group and $4(16.0 \%)$ in the placebo group had an atherogenic dyslipidemia and at study end 4 patients in the verum group (13.8\%) and $3(12.0 \%)$ in the placebo group.

\section{LV function}

In all patients at baseline the right ventricular end diastolic diameter (RVEDD), left atrium (LA), left ventricular end systolic diameter (LVESD), left ventricular end diastolic diameter (LVEDD), left ventricular ejection fraction (LVEF), intraventricular septum (IVS) and left ventricular posterior wall (LVPW) were in normal range. However, patients with LVEF $54-65 \%$ showed a significant increase of $\operatorname{LVEF}(p=0.020, \mathrm{ES}=0.995, \mathrm{Q} 1 ; \mathrm{Q} 3$ : $0.5 ; 15.0$ ) in the verum group after intervention (Table 2).

After dietary intervention the LV mass index (LVMI) was significantly reduced in the verum group $(p=0.003$, $\mathrm{ES}=0.260, \mathrm{Q} 1 ; \mathrm{Q} 3:-26.5 ;-2.2)$. If a distinction is made between male and female this parameter is significantly reduced too, especially by reducing of this parameter in woman $(p=0.035)$. The LVEDD $(p=0.050, \mathrm{ES}=0.210$, Q1/Q3: -5.0; 1.0) were reduced and $\mathrm{E} / \mathrm{A}$ ratio $(p=0.051$, $\mathrm{ES}=0.401$, Q1; Q3: -0.04; 0.27) in normal range was improved. In the placebo group these results were not 
Table 1 Baseline characteristics

\begin{tabular}{|c|c|c|c|}
\hline & $\begin{array}{l}\text { Verum }(n=29) \\
x \pm S D\end{array}$ & $\begin{array}{l}\text { Placebo }(n=25) \\
x \pm S D\end{array}$ & $\begin{array}{l}\text { V vs. P } \\
p \text {-value }\end{array}$ \\
\hline \multicolumn{4}{|l|}{$\operatorname{Sex}(n / \%)$} \\
\hline female & $14(48.3 \%)$ & $13(52.0 \%)$ & 1.000 \\
\hline male & $15(51.7 \%)$ & $12(48.0 \%)$ & \\
\hline Age (years) & $59.7 \pm 10.2$ & $59.8 \pm 13.8$ & 0.524 \\
\hline Height (cm) & $171.9 \pm 8.8$ & $171.0 \pm 9.1$ & 0.740 \\
\hline Weight (kg) & $82.0 \pm 17.9$ & $82.9 \pm 14.7$ & 0.561 \\
\hline BMI $\left(\mathrm{kg} / \mathrm{m}^{2}\right)$ & $27.6 \pm 4.8$ & $28.3 \pm 4.2$ & 0.535 \\
\hline$<25.0 \mathrm{~kg} / \mathrm{m}^{2}(\mathrm{n} / \%)$ & $10(34.5 \%)$ & $7(28.0 \%)$ & 0.940 \\
\hline $25.0-29.9 \mathrm{~kg} / \mathrm{m}^{2}$ (n/\%) & $11(37.9 \%)$ & $11(44.0 \%)$ & \\
\hline$\geq 30.0 \mathrm{~kg} / \mathrm{m}^{2}(\mathrm{n} / \%)$ & $8(27.6 \%)$ & $7(28.0 \%)$ & \\
\hline WC female $(\mathrm{cm})$ & $88.9 \pm 13.1$ & $87.6 \pm 9.6$ & 0.847 \\
\hline$\geq 88 \mathrm{~cm}(\mathrm{n} / \%)$ & $9(31.0 \%)$ & $5(20.0 \%)$ & 0.449 \\
\hline WC male $(\mathrm{cm})$ & $103.6 \pm 14.6$ & $106.6 \pm 8.8$ & 0.286 \\
\hline$\geq 102 \mathrm{~cm}(\mathrm{n} / \%)$ & $8(27.6 \%)$ & $9(36.0 \%)$ & 0.429 \\
\hline $\mathrm{WHtR}$ & $0.558 \pm 0.080$ & $0.565 \pm 0.064$ & 0.602 \\
\hline$\geq 0,5(n / \%)$ & $21(72.4 \%)$ & $20(80.0 \%)$ & 0.545 \\
\hline BP systolic (mmHg) & $142.2 \pm 17.4$ & $134.7 \pm 12.5$ & 0.077 \\
\hline$\geq 130 \mathrm{mmHg}(\mathrm{n} / \%)$ & $23(79.3 \%)$ & $16(64.0 \%)$ & 0.239 \\
\hline BP diastolic (mmHg) & $86.3 \pm 9.7$ & $82.2 \pm 8.6$ & 0.160 \\
\hline$\geq 85 \mathrm{mmHg}(\mathrm{n} / \%)$ & $16(55.2 \%)$ & $9(36.0 \%)$ & 0.182 \\
\hline Heart rate/min & $71.4 \pm 12.5$ & $72.9 \pm 12.7$ & 0.773 \\
\hline
\end{tabular}

Abbreviations: $B M I$ body mass index, WC waist circumference, WHtR waist to height ratio, $B P$ blood pressure

found. But the differences between these both groups are statistical not significant.

The linear regression analysis showed that LVMI in the verum group depended on the initial value and the magnesium concentration in the serum during the course of the study. The change of LVMI is depending on the alteration in HDL-C and diastolic blood pressure. Only in the verum group the favourable changes of LVMI were found under this condition. In contrast, these results could not be shown in the placebo group (Table 3).

The interventricular septal thickness was reduced in tendency only in the verum group $(p=0.053, \mathrm{ES}=0.348$, Q1; Q3: -2.0;0.5), while LVPW was unchanged in both groups. On the other hand, the LA parameters were significantly increased in the verum group after intervention but within the normal range $(p=0.018, \mathrm{ES}=0.314$, Q1; Q3: -0.75; 3.75) (Table 2). Furthermore could be demonstrated a strong correlation between LVMI and LA in men $(p=0.018)$, but not in female $(p=0.225)$.

When looking at the results broken down by HOMA quartiles and parameters of LV function it can be noted, that in female diameter of LA increases age-adjusted significantly with the quartiles $(p=0.001)$ and in male the
LVEDD $(p=0.055)$ (Table 4). The influence of HOMAquartiles was proofed by a regression model.

\section{HOMA-IR}

In the verum group abnormal fasting plasma glucose $\geq 5.6 \mathrm{mmol} / \mathrm{l}$ was distinctly reduced after 6 weeks of dietary intervention compared to baseline $(p=0.055, \mathrm{ES}=$ $0.388, \mathrm{Q} 1$; $3:-1.30 ;-0.11)$, in the placebo group this difference was not found $(p=0.328, \mathrm{ES}=0.604, \mathrm{Q} 1 ; \mathrm{Q} 3$ : $-0.94 ; 0.28)$.

At baseline, elevated fasting insulin concentration $(\geq 58$ $\mathrm{pmol} / \mathrm{l}$ ) was recorded in 19 patients of the verum group and in 17 patients of the placebo group, a normal level $(<58 \mathrm{pmol} / \mathrm{l})$ in 10 patients in the verum group vs. 8 patients in the placebo group. But only in the verum group it was in tendency reduced after intervention $(p=0.053, \mathrm{ES}=0.232, \mathrm{Q} 1 ; \mathrm{Q} 3:-35.1 ; 9.4)$, and significantly in patients with fasting insulin $\geq 58 \mathrm{pmol} / \mathrm{l}$ $(p=0.020, \mathrm{ES}=0.340, \mathrm{Q} 1 ; \mathrm{Q} 3:-42.7 ; 1.4)$.

Elevated HOMA-IR $>2.5$ was found in 14 patients in the verum group, and 11 patients in the placebo group. An euglycaemic IR (FPG $<5.6 \mathrm{mmol} / \mathrm{l}, \mathrm{HOMA}-\mathrm{IR} \geq 2.5$ ) showed at baseline 8 patients in the verum group and 4 patients in the placebo group. HOMA-IR was in tendency reduced in the verum group $(p=0.053, \mathrm{ES}=$ 0.218 , Q1;Q3: $-1.25 ; 0.25)$ at the end of study, particularly for patients with HOMA-IR $>2.5$ in the verum group $(p=0.068, \mathrm{ES}=0.340, \mathrm{Q} 1 ; \mathrm{Q} 3:-2.90 ;-0.22) \quad($ Table 5). At the study end only 3 patients had a HOMA-IR $\geq$ $2.5(p=0.063)$, and in the placebo group 2 patients a HOMA-IR $\geq 2.5(p=0.625)$.

\section{Other biochemistry cardiovascular risk factors}

All relevant biochemical parameters are summarized in Table 5. In the blood cell count up to a significant reduction of leucocytes in normal range in the verum group $(p<0.05)$ all components were in normal range in the verum as well as the placebo group. Total cholesterol (TC) was unchanged in verum and placebo group after dietary intervention. LDL-cholesterol (LDL-C) was nearly unchanged in the verum group, and in the placebo group slightly reduced; HDL-C was unchanged in both groups. After dietary intervention TG were significantly increased in the verum group $(p=0.011$, $\mathrm{ES}=0.292$, Q1;Q3: -0.01;0.30), but unchanged in the placebo group. TG concentrations $\geq 1.7 \mathrm{mmol} / \mathrm{l}$ were found at baseline in $27.6 \%$ of patients in the verum group and $28.0 \%$ in the placebo group. At study end this relation was 31.0 to $20.0 \%$.

Renal function measured by creatinine and glomerular filtration rate (GFR) was normal in all patients. The changes in serum magnesium was significantly higher compared to the placebo group after intervention $(p=0.005$, $\mathrm{ES}=0.708, \mathrm{Q} 1 ; \mathrm{Q} 3:-0.02 ; 0.05$ vs. $-0.06 ; 0.01)$. The serum 
Table 2 Changing of patient's characteristics: comparison of echocardiographic values before and after dietary intervention

\begin{tabular}{|c|c|c|c|c|c|c|}
\hline & \multicolumn{3}{|c|}{ Verum $(n=29) \times \pm S D$} & \multicolumn{3}{|c|}{ Placebo $(n=25) \times \pm$ SD } \\
\hline & Baseline & Week 6 & Diff & Baseline & Week 6 & Diff \\
\hline $\mathrm{LA}(\mathrm{mm})$ & $35.8 \pm 5.9$ & $37.1 \pm 5.0$ & $1.39 \pm 2.92^{\#}$ & $36.4 \pm 6.4$ & $35.8 \pm 6.1$ & $-0.68 \pm 4.26$ \\
\hline RVEDD (mm) & $26.8 \pm 5.3$ & $26.3 \pm 3.4$ & $-0.52 \pm 4.67$ & $25.2 \pm 4.1$ & $25.1 \pm 3.5$ & $-0.08 \pm 4.29$ \\
\hline LVEDD (mm) & $49.0 \pm 5.7$ & $47.6 \pm 7.1$ & $-1.34 \pm 5.47^{\#}$ & $47.9 \pm 6.9$ & $48.4 \pm 7.5$ & $0.52 \pm 5.64$ \\
\hline $\operatorname{LVESD}(\mathrm{mm})$ & $30.4 \pm 4.9$ & $30.1 \pm 5.5$ & $-0.31 \pm 3.27$ & $29.5 \pm 5.2$ & $30.2 \pm 6.7$ & $0.72 \pm 4.20$ \\
\hline LVEF (\%) & $68.6 \pm 8.3$ & $70.2 \pm 9.0$ & $1.66 \pm 8.94$ & $70.0 \pm 9.3$ & $70.3 \pm 8.9$ & $0.28 \pm 10.81$ \\
\hline$<65 \%(n / \%)$ & $10(34.5 \%)$ & $9(31.0 \%)$ & - & $6(24.0 \%)$ & $7(28.0 \%)$ & - \\
\hline$<65 \%$ & $59.5 \pm 4.2$ & $66.8 \pm 9.5$ & $7.30 \pm 8.22^{\#}$ & $57.5 \pm 5.4$ & $64.5 \pm 11.8$ & $7.00 \pm 7.75$ \\
\hline$\geq 65 \%$ & $73.5 \pm 5.5$ & $72.5 \pm 8.4$ & $-1.00 \pm 8.07$ & $74.0 \pm 6.3$ & $72.1 \pm 7.3$ & $-1.84 \pm 10.93$ \\
\hline IVS (mm) & $10.6 \pm 1.6$ & $9.9 \pm 1.9$ & $-0.62 \pm 1.78$ & $10.6 \pm 1.4$ & $10.2 \pm 1.5$ & $-0.44 \pm 1.32$ \\
\hline LVPW (mm) & $10.7 \pm 1.6$ & $10.3 \pm 1.6$ & $-0.41 \pm 1.52$ & $10.4 \pm 1.5$ & $10.2 \pm 1.6$ & $-0.20 \pm 1.12$ \\
\hline$E / E^{\prime}>8(n / \%)$ & $2(25.0 \%)$ & $3(37.5 \%)$ & - & $2(33.3 \%)$ & $0(0.0 \%)$ & - \\
\hline E wave & $0.73 \pm 0.19$ & $0.71 \pm 0.16$ & $-0.02 \pm 0.18$ & $0.73 \pm 0.18$ & $0.72 \pm 0.15$ & $-0.01 \pm 0.15$ \\
\hline A wave & $0.74 \pm 0.24$ & $0.68 \pm 0.28$ & $-0.06 \pm 0.19$ & $0.71 \pm 0.18$ & $0.73 \pm 0.15$ & $0.01 \pm 0.16$ \\
\hline E/A ratio & $1.05 \pm 0.35$ & $1.18 \pm 0.49$ & $0.13 \pm 0.38^{\#}$ & $1.45 \pm 2.04$ & $1.02 \pm 0.21$ & $-0.42 \pm 2.04$ \\
\hline LVMI g/m2 & $98.2 \pm 24.4$ & $90.0 \pm 37.0$ & $-8.15 \pm 35.48^{\# \#}$ & $93.5 \pm 26.5$ & $90.9 \pm 25.9$ & $-2.61 \pm 21.20$ \\
\hline LVMI $\mathrm{g} / \mathrm{m}^{2}$ female & $87.2 \pm 16.6$ & $77.7 \pm 20.9$ & $-9.5 \pm 15.6 \#$ & $89.0 \pm 26.2$ & $80.2 \pm 21.8$ & $-8.7 \pm 23.1$ \\
\hline LVMI g/m² male & $108.4 \pm 26.4$ & $101.5 \pm 45.1$ & $-6.9 \pm 47 \#$ & $98.4 \pm 27.1$ & $102.4 \pm 25.9$ & $4.0 \pm 17.5$ \\
\hline
\end{tabular}

Abbreviations: LA, left atrium; RVEDD, right ventricular end diastolic diameter; LVEDD, left ventricular end diastolic diameter; LVESD, left ventricular end systolic diameter; LVEF, left ventricular ejection fraction; IVS, interventricular septum; LVPW, left ventricular posterior wall; E/A ratio, ratio of the early (E) to late (A) ventricular filling velocities; LVMI, Left ventricular mass index

${ }^{\mathrm{a}} n=14$ (verum)/ $n=13$ (placebo, ${ }^{\mathrm{b}} n=15$ (verum) $/ n=12$ (placebo)

$\# p<0.05$ within the group, \#\# $p<0.01$ within the group

potassium level was significantly increased after intervention in the verum group $(p=0.034, \mathrm{ES}=0.512, \mathrm{Q} 1 ; \mathrm{Q} 3$ : $0.0 ; 0.3$ vs. $-0.5 ; 0.1)$, compared to the placebo group. However, the increase of both serum magnesium as well as potassium after intervention was in normal range.

In $24 \mathrm{~h}$ urinary collection potassium excretion $(p=0.059$, $\mathrm{ES}=0.326$, Q1;Q3: -7.2;30.2) as well as magnesium excretion were elevated $(p=0.018, \mathrm{ES}=0.507, \mathrm{Q} 1 ; \mathrm{Q} 3:-0.18 ; 1.66)$ in the verum group. The magnesium excretion was significant compared to the placebo group too $(p=0.036, \mathrm{ES}=$ 0.377, Q1;Q3: -0.13;1.51 vs. -0.64;0.46). This result was an effect of compliance. The normal renal function could be shown in $24 \mathrm{~h}$ urinary collection: albumin excretion as well as the quotient albumin/creatinine/ $24 \mathrm{~h}$ was in normal range. Only in the verum group this quotient was in tendency reduced after dietary intervention, while in the placebo group this quotient was increased. This difference in both groups was reduced ( $p=0.083, \mathrm{ES}=0.521, \mathrm{Q} 1$;Q3: $-0.09 ; 0.03$ vs. $-0.05 ; 0.22)$.

\section{Rhythm disturbances}

In this pilot study a reduction of PBs could be observed in the verum group, but this result was not significant, probably due to the small number of patients and an enormous variance of the PBs. On the other hand, in the placebo group the reduction of VPBs was remarkable with the same enormous variance as in the verum group $(p=0.005$, $\mathrm{ES}=0.369$, Q1;Q3: -935.0;5.0). The heart rate was

Table 3 Changing of LVMI depending on alteration in HDL-Cholesterol and diastolic blood pressure

\begin{tabular}{|c|c|c|c|c|c|}
\hline & \multirow{2}{*}{$\begin{array}{l}\text { total } \\
\mathrm{p}_{\text {ANOVA }}\end{array}$} & \multicolumn{4}{|c|}{ Depending variable: Regression coefficient B ( $p$-value) } \\
\hline & & LVMI Baseline & Serum-Mg Week 6 & Changing of & \\
\hline \multirow[t]{2}{*}{ Verum $(n=29)$} & 0,008 & 0,014 & 0,002 & $\mathrm{HDL}-\mathrm{C}$ & $-0,567^{1}(0,507)$ \\
\hline & 0,003 & 0,011 & 0,004 & BP diastolic & $1,623^{2}(0,129)$ \\
\hline \multirow[t]{2}{*}{ Placebo $(n=25)$} & 0,069 & 0,014 & 0,257 & $\mathrm{HDL}-\mathrm{C}$ & $0,697(0,283)$ \\
\hline & 0,109 & 0,020 & 0,421 & BP diastolic & $-0,164(0,780)$ \\
\hline
\end{tabular}

Modell of linear regression, depending variable: changing of LVMI, age adjusted

Abbreviations: $L V M I$ left ventricular mass index, Serum-Mg serum magnesium, $H D L-C H D L$ cholesterol, BP blood pressure

${ }^{1}$ Increase of HDL-C correlates with decrease of LVMI

${ }^{2}$ Decrease of BP diastolic correlates with decrease of LVMI 
Table 4 HOMA-quartiles for LVMI, LA, IVS, PW, and LVEDD in male and female

\begin{tabular}{|c|c|c|c|c|c|}
\hline HOMA-quartile & 1: $0.7 \ldots 1.5$ & $2: 1.6 \ldots 2.4$ & $3: 2.5 \ldots 4.3$ & $4:>4.3$ & $p$-value \\
\hline N (male/female) & $7 / 7$ & $5 / 8$ & $5 / 9$ & $10 / 3$ & \\
\hline LVMI (male) & $96.1+/-36.8$ & $106.2+/-23.2$ & $102.9+/-35.9$ & $108.9+/-16.4$ & 0.372 \\
\hline LVMI (female) & $80.6+/-19.4$ & $95.7+/-25.1$ & $90.7+/-21.4$ & $78.6+/-13.5$ & 0.967 \\
\hline LA (male) & $37.3+/-7.6$ & $38.0+/-7.2$ & $37.0+/-4.8$ & $41.4+/-4.2$ & 0.118 \\
\hline LA (female) & $29.1+/-2.5$ & $32.0+/-2.6$ & $34.0+/-5.6$ & $40.3+/-4.0$ & 0.001 \\
\hline IVS (male) & $11.6+/-1.8$ & $11.2+/-1.3$ & $10.8+/-1.8$ & $11.0+/-1.3$ & 0.533 \\
\hline IVS (female) & $9.6+/-1.4$ & $9.8+/-1.3$ & $10.8+/-1.2$ & $9.3+/-1.2$ & 0.489 \\
\hline PW (male) & $11.3+/-1.9$ & $11.4+/-1.5$ & $11.0+/-2.0$ & $11.3+/-1.4$ & 0.880 \\
\hline PW (female) & $9.4+/-1.5$ & $9.6+/-0.7$ & $10.3+/-1.4$ & $10.0+/-1.0$ & 0.205 \\
\hline LVEDD (male) & $47.0+/-8.5$ & $50.0+/-7.1$ & $51.4+/-6.7$ & $53.5+/-4.1$ & 0.055 \\
\hline LVEDD (female) & $43.1+/-4.8$ & $49.8+/-4.5$ & $44.9+/-4.5$ & $47.3+/-3.2$ & 0.562 \\
\hline
\end{tabular}

Abbreviations: HOMA Homeostasis Model Assessment, LVMI left ventricular mass index, LA left atrium, IVS interventricular septum, PW posterior wall, LVEDD left ventricular end diastolic diameter

decreased only in the verum group $(p=0.027, \mathrm{ES}=0.256$, Q1;Q3: -7.8;0.8) (Table 6).

A change of awareness of symptoms measured by a visual analogue scale (VAS points) also could not be found.

\section{Discussion}

\section{Metabolic syndrome and its components}

The MetS is the burden of our century and in Germany could be found with prevalence depending on the region between 14 and $23 \%$ [34].

Precursors of MetS like disturbed glucose tolerance, triggered by elevated fasting insulin followed by IR, lead already at early stage to structural changes of the left ventricle and influence on diastolic function. These factors seem to be acting independently from CAD associated especially with diastolic dysfunction or heart failure $[4,5,35]$. Our knowledge based on experimental [36] and clinical studies concerning the MetS $[4,5,37,38]$ as well as meta-analyses [28].

The influence of micronutrients on these pathological processes in MetS is only partially known. There is evidence that magnesium plays an important role, especially in the glucose metabolism [10]. In addition, a positive effect on glucose metabolism is discussed for magnesium and for coenzyme Q10 [21, 24]. The effects of coenzyme Q10 on the glucose metabolism may be based on multifactorial mechanisms i.e. by reduction of oxidative stress $[39,40]$.

On average, the patients enrolled in this study were overweight, with abdominal obesity measured by WC and also by WHtR. These basic components of MetS as well as fasting plasma glucose were unchanged after intervention. The reduction of systolic blood pressure in the verum group at study end has not influenced this result. Therefore we did not found a reduction of the components of MetS in verum group. The results of this post hoc analysis seem to suggest that this specific combination of micronutrients improves the cardiometabolic profile in patients with CA.

\section{LV function}

The MetS and its components - IR/T2DM, AH and abdominal obesity - are associated with impaired mitochondrial function and increased oxidative stress. These pathophysiological mechanisms contribute to the development of diastolic dysfunction [4, 35, 37, 38]. Ikee et al. [41] found that diastolic dysfunction at first is an asymptomatic disorder of relaxation and/or compliance associated with normal systolic pump function. It depends on preload, end diastolic pressure and structure of the LV wall.

We found signs of preclinical LV diastolic dysfunction parallel to metabolic changes. This is consistent with the results of this pilot study in comparison of the verum and placebo group. At baseline the E/A ratio was in tendency lower in the verum group than in the placebo group. After intervention E/A ratio was significantly improved in the verum group, but not in the placebo group. Diastolic dysfunction assessed with the use of E/ A worsened with the number of components of MetS [42]. The changes in diastolic function are age related $[32,42,43]$ and furthermore depending on components of MetS like overweight, T2DM, AH, and CAD [4, 35]. Furthermore, the present study showed that the LVEF could only be improved if it was within the lower normal range (54-65\%). Magnesium leads to an economization of cardiac pump function [44]. In a review it could be shown that also CoQ10 improves parameters of heart function like ejection fraction in heart failure [45]. This could be confirmed with this study: the results demonstrate a significant improvement of $\mathrm{EF} \leq 65 \%$ in the verum group, but this effect was not significant between the both study groups (Table 2). 
Table 5 Changing of patient's characteristics: comparison of biochemical values before and after dietary intervention

\begin{tabular}{|c|c|c|c|c|c|c|}
\hline & Verum $(n=29$ & & & Placebo $(n=2$ & $\pm \mathrm{SD}$ & \\
\hline & Baseline & Week 6 & Diff & Baseline & Week 6 & Diff \\
\hline $\operatorname{CrP}(\mathrm{nmol} / \mathrm{l})$ & $26.0 \pm 28.7$ & $24.8 \pm 22.6$ & $-1.22 \pm 23.37$ & $20.8 \pm 19.8$ & $29.8 \pm 42.1$ & $9.07 \pm 39.52$ \\
\hline$<10 \mathrm{nmol} / \mathrm{l}(\mathrm{n} / \%)$ & $9(31.0 \%)$ & $9(31.0 \%)$ & - & $10(40.0 \%)$ & $12(48.0 \%)$ & - \\
\hline $10-30 \mathrm{nmol} / \mathrm{l}(\mathrm{n} / \%)$ & $13(44.8 \%)$ & $13(44.8 \%)$ & & $10(40.0 \%)$ & $6(24.0 \%)$ & \\
\hline > $30 \mathrm{nmol} / \mathrm{l}(\mathrm{n} / \%)$ & $7(24.1 \%)$ & $7(24.1 \%)$ & & $5(20.0 \%)$ & $7(28.0 \%)$ & \\
\hline FPG (mmol/l) & $5.49 \pm 1.58$ & $5.30 \pm 1.28$ & $-0.20 \pm 0.75$ & $5.35 \pm 0.65$ & $5.15 \pm 0.77$ & $-0.20 \pm 0.63^{\#}$ \\
\hline$<5.6 \mathrm{mmol} / \mathrm{l}$ & $4.76 \pm 0.54$ & $4.79 \pm 0.62$ & $0.03 \pm 0.39$ & $5.04 \pm 0.27$ & $4.91 \pm 0.70$ & $-0.13 \pm 0.58$ \\
\hline$\geq 5.6 \mathrm{mmol} / \mathrm{l}$ & $7.12 \pm 1.94$ & $6.42 \pm 1.67$ & $-0.70 \pm 1.10$ & $6.15 \pm 0.65$ & $5.79 \pm 0.56$ & $-0.36 \pm 0.75$ \\
\hline HbA1c (\%) & $5.77 \pm 0.68$ & $5.76 \pm 0.63$ & $-0.01 \pm 0.35$ & $5.64 \pm 0.39$ & $5.66 \pm 0.33$ & $0.02 \pm 0.39$ \\
\hline $\mathrm{F}$ Insulin $(\mathrm{pmol} /)^{\mathrm{a}}$ & $113.9 \pm 127.5$ & $89.5 \pm 75.8$ & $-24.4 \pm 73.4$ & $83.6 \pm 44.9$ & $71.3 \pm 51.3$ & $-12.3 \pm 54.0$ \\
\hline$<58 \mathrm{pmol} / \mathrm{l}(\mathrm{n} / \%)$ & $10(34.5 \%)$ & 11 (37.9\%) & - & $8(32.0 \%)$ & $10(40.0 \%)$ & - \\
\hline$<58 \mathrm{pmol} / \mathrm{l}$ & $39.2 \pm 9.9$ & $44.7 \pm 18.4$ & $5.2 \pm 19.5$ & $41.3 \pm 13.5$ & $40.4 \pm 13.3$ & $-0.9 \pm 16.0$ \\
\hline$\geq 58 \mathrm{pmol} / \mathrm{l}$ & $153.1 \pm 143.2$ & $113.1 \pm 84.0$ & $-39.9 \pm 86.3^{\#}$ & $103.5 \pm 40.0$ & $85.9 \pm 56.3$ & $-17.7 \pm 64.6$ \\
\hline $\mathrm{HOMA}-\mathrm{R}^{\mathrm{a}}$ & $4.93 \pm 9.18$ & $3.39 \pm 4.00$ & $-1.54 \pm 5.69^{\#}$ & $2.97 \pm 1.86$ & $2.50 \pm 2.17$ & $-0.47 \pm 2.26$ \\
\hline$\leq 2.5(\mathrm{n} / \%)$ & 15 (51.7\%) & 20 (69.0\%) & - & 14 (56.0\%) & 18 (72.0\%) & - \\
\hline$\leq 2.5$ & $1.55 \pm 0.52$ & $1.57 \pm 0.59$ & $0.03 \pm 0.56$ & $1.66 \pm 0.52$ & $1.95 \pm 2.19$ & $0.29 \pm 2.02$ \\
\hline$>2.5$ & $8.56 \pm 12.40$ & $5.34 \pm 5.12$ & $-3.22 \pm 7.97$ & $4.64 \pm 1.60$ & $3.20 \pm 2.03$ & $-1.44 \pm 2.28$ \\
\hline $\mathrm{Na}(\mathrm{mmol} / \mathrm{l})$ & $143.0 \pm 4.5$ & $142.2 \pm 2.7$ & $-0.76 \pm 4.25$ & $141.9 \pm 2.5$ & $141.6 \pm 2.8$ & $-0.28 \pm 2.51$ \\
\hline$<140 \mathrm{mmol} / \mathrm{l}$ & $138.0 \pm 1.2$ & $139.0 \pm 3.5$ & $1.00 \pm 2.83$ & $138.4 \pm 0.9$ & $138.8 \pm 4.4$ & $0.40 \pm 4.22$ \\
\hline$\geq 140 \mathrm{mmol} / \mathrm{l}$ & $143.8 \pm 4.3$ & $142.8 \pm 2.2$ & $-1.04 \pm 4.41$ & $142.8 \pm 2.0$ & $142.4 \pm 1.7$ & $-0.45 \pm 2.01$ \\
\hline $\mathrm{K}(\mathrm{mmol} / \mathrm{l})$ & $4.44 \pm 0.53$ & $4.55 \pm 0.43$ & $0.11 \pm 0.44$ & $4.59 \pm 0.37$ & $4.50 \pm 0.31$ & $-0.09 \pm 0.33^{*}$ \\
\hline$<4.0 \mathrm{mmol} / \mathrm{l}$ & $3.72 \pm 0.17$ & $4.08 \pm 0.34$ & $0.35 \pm 0.26$ & 3.70 & 4.10 & 0.40 \\
\hline$\geq 4.0 \mathrm{mmol} / \mathrm{l}$ & $4.56 \pm 0.47$ & $4.62 \pm 0.40$ & $0.07 \pm 0.45$ & $4.63 \pm 0.33$ & $4.52 \pm 0.31$ & $-0.11 \pm 0.32$ \\
\hline $\mathrm{Mg}(\mathrm{mmol} / \mathrm{l})$ & $0.845 \pm 0.069$ & $0.858 \pm 0.068$ & $0.013 \pm 0.047$ & $0.874 \pm 0.084$ & $0.851 \pm 0.068$ & $-0.024 \pm 0.056^{\# * *}$ \\
\hline$<0.75 \mathrm{mmol} / \mathrm{l}$ & $0.727 \pm 0.023$ & $0.773 \pm 0.021$ & $0.048 \pm 0.035$ & 0.72 & 0.77 & 0.05 \\
\hline$\geq 0.75 \mathrm{mmol} / \mathrm{l}$ & $0.859 \pm 0.058$ & $0.867 \pm 0.068$ & $0.009 \pm 0.047$ & $0.881 \pm 0.079$ & $0.854 \pm 0.068$ & $-0.027 \pm 0.055^{\# \# * *}$ \\
\hline $\mathrm{Cl}(\mathrm{mmol} / \mathrm{l})$ & $102.0 \pm 3.4$ & $100.9 \pm 2.6$ & $-1.03 \pm 3.80$ & $101.4 \pm 2.6$ & $101.4 \pm 3.2$ & $0.00 \pm 3.20$ \\
\hline$<100 \mathrm{mmol} / \mathrm{l}$ & $98.0 \pm 1.2$ & $99.6 \pm 2.4$ & $1.57 \pm 2.51$ & $97.8 \pm 1.0$ & $100.2 \pm 2.5$ & $2.33 \pm 2.88$ \\
\hline$\geq 100 \mathrm{mmol} / \mathrm{l}$ & $103.2 \pm 2.8$ & $101.4 \pm 2.5$ & $-1.86 \pm 3.81^{\#}$ & $102.6 \pm 1.8$ & $101.8 \pm 3.4$ & $-0.74 \pm 3.00$ \\
\hline Creatinine $(\mu \mathrm{mol} / \mathrm{l})$ & $77.4 \pm 14.6$ & $76.4 \pm 14.9$ & $-0.95 \pm 6.98$ & $76.6 \pm 17.4$ & $75.3 \pm 16.4$ & $-1.31 \pm 7.02$ \\
\hline GFR (ml/min) & $83.6 \pm 13.9$ & $85.4 \pm 14.9$ & $1.79 \pm 8.09$ & $86.1 \pm 16.0$ & $86.8 \pm 16.3$ & $0.76 \pm 6.48$ \\
\hline TC (mmo/l) & $4.97 \pm 1.00$ & $5.12 \pm 1.09$ & $0.15 \pm 0.66$ & $5.25 \pm 0.94$ & $5.10 \pm 1.04$ & $-0.15 \pm 0.69$ \\
\hline$\geq 5.2 \mathrm{mmol} / \mathrm{l}$ & $5.74 \pm 0.63$ & $6.08 \pm 0.79$ & $0.34 \pm 0.85$ & $5.86 \pm 0.75$ & $5.89 \pm 0.67$ & $0.03 \pm 0.37$ \\
\hline LDL-C (mmol/l) & $3.14 \pm 0.97$ & $3.10 \pm 0.83$ & $-0.04 \pm 0.44$ & $3.39 \pm 0.92$ & $3.30 \pm 0.97$ & $-0.09 \pm 0.45$ \\
\hline$<2.6 \mathrm{mmol} / \mathrm{l}$ & $2.02 \pm 0.27$ & $2.27 \pm 0.48$ & $0.25 \pm 0.45$ & $2.11 \pm 0.56$ & $2.33 \pm 0.32$ & $0.22 \pm 0.25$ \\
\hline$\geq 2.6 \mathrm{mmol} / \mathrm{l}$ & $3.59 \pm 0.76$ & $3.43 \pm 0.70$ & $-0.15 \pm 0.40$ & $3.64 \pm 0.76$ & $3.48 \pm 0.94$ & $-0.15 \pm 0.46$ \\
\hline$<3.3 \mathrm{mmol} / \mathrm{l}$ & $2.43 \pm 0.48$ & $2.59 \pm 0.51$ & $0.16 \pm 0.36$ & $2.72 \pm 0.57^{*}$ & $2.67 \pm 0.40$ & $-0.05 \pm 0.33$ \\
\hline$\geq 3.3 \mathrm{mmol} / \mathrm{l}$ & $4.08 \pm 0.55$ & $3.78 \pm 0.68$ & $-0.30 \pm 0.41^{\#}$ & $4.01 \pm 0.71$ & $3.88 \pm 0.99$ & $-0.14 \pm 0.54$ \\
\hline $\mathrm{HDL}-\mathrm{C}(\mathrm{mmol} / \mathrm{l})$ & $1.40 \pm 0.41$ & $1.39 \pm 0.43$ & $-0.01 \pm 0.17$ & $1.45 \pm 0.47$ & $1.40 \pm 0.42$ & $-0.05 \pm 0.17$ \\
\hline TG $(\mathrm{mmol} / \mathrm{l})$ & $1.56 \pm 0.77$ & $1.97 \pm 1.86$ & $0.42 \pm 1.30^{\#}$ & $1.34 \pm 0.53$ & $1.36 \pm 0.50$ & $0.02 \pm 0.58$ \\
\hline$\geq 1.7 \mathrm{mmol} / \mathrm{l}$ & $2.63 \pm 0.57$ & $3.71 \pm 2.95$ & $1.08 \pm 2.41$ & $2.08 \pm 0.28^{*}$ & $1.71 \pm 0.61$ & $-0.37 \pm 0.76$ \\
\hline Uric acid $(\mu \mathrm{mol} / \mathrm{l})$ & $338 \pm 90$ & $331 \pm 80$ & $-7.2 \pm 42.1$ & $315 \pm 100$ & $308 \pm 91$ & $-6.9 \pm 39.9$ \\
\hline Gamma-GT ( $\mu$ kat/l) & $0.64 \pm 0.83$ & $0.63 \pm 0.72$ & $-0.01 \pm 0.17$ & $0.53 \pm 0.29$ & $0.52 \pm 0.26$ & $-0.01 \pm 0.17$ \\
\hline ASAT $(\mu k a t / l)$ & $0.42 \pm 0.20$ & $0.42 \pm 0.11$ & $0.00 \pm 0.14$ & $0.40 \pm 0.11$ & $0.40 \pm 0.13$ & $0.00 \pm 0.09$ \\
\hline
\end{tabular}


Table 5 Changing of patient's characteristics: comparison of biochemical values before and after dietary intervention (Continued)

\begin{tabular}{|c|c|c|c|c|c|c|}
\hline & \multicolumn{3}{|c|}{ Verum $(n=29) \times \pm S D$} & \multicolumn{3}{|c|}{ Placebo $(n=25) \times \pm S D$} \\
\hline & Baseline & Week 6 & Diff & Baseline & Week 6 & Diff \\
\hline ALAT ( $\mu$ kat/l) & $0.47 \pm 0.24$ & $0.46 \pm 0.21$ & $-0.02 \pm 0.16$ & $0.43 \pm 0.26$ & $0.45 \pm 0.28$ & $0.02 \pm 0.11$ \\
\hline TSH ( $\mu \mathrm{I} \mathrm{U} / \mathrm{ml})$ & $2.15 \pm 1.17$ & $1.96 \pm 1.06$ & $-0.19 \pm 0.52^{\#}$ & $2.19 \pm 1.20$ & $1.92 \pm 1.00$ & $-0.28 \pm 0.57^{\#}$ \\
\hline \multicolumn{7}{|l|}{$24 \mathrm{~h}$ urinary collection } \\
\hline $\mathrm{Na}(\mathrm{mmol} / 24 \mathrm{~h})$ & $193.7 \pm 73.6$ & $186.7 \pm 76.0$ & $-7.0 \pm 79.7$ & $167.9 \pm 53.5$ & $177.4 \pm 64.1$ & $9.5 \pm 46.8$ \\
\hline $\mathrm{K}(\mathrm{mmol} / 24 \mathrm{~h})$ & $68.2 \pm 25.3$ & $76.6 \pm 26.2$ & $8.4 \pm 28.0$ & $67.3 \pm 19.3$ & $71.6 \pm 22.5$ & $4.2 \pm 18.0$ \\
\hline K i.S./K (24 h) & $0.072 \pm 0.023$ & $0.067 \pm 0.027$ & $-0.005 \pm 0.028$ & $0.076 \pm 0.034$ & $0.069 \pm 0.021$ & $-0.008 \pm 0.030$ \\
\hline $\mathrm{Mg}(\mathrm{mmol} / 24 \mathrm{~h})$ & $4.03 \pm 1.14$ & $4.79 \pm 1.79$ & $0.76 \pm 1.85^{\#}$ & $3.78 \pm 1.45$ & $3.86 \pm 1.88$ & $0.08 \pm 1.75^{*}$ \\
\hline Mg i.S./Mg (24h) & $0.227 \pm 0.070$ & $0.221 \pm 0.162$ & $-0.006 \pm 0.180$ & $0.260 \pm 0.095$ & $0.268 \pm 0.121$ & $0.008 \pm 0.093$ \\
\hline $\mathrm{Cl}(\mathrm{mmol} / 24 \mathrm{~h})$ & $175.6 \pm 70.2$ & $174.9 \pm 76.9$ & $-0.72 \pm 74.63$ & $153.5 \pm 54.9$ & $161.2 \pm 70.7$ & $7.72 \pm 43.40$ \\
\hline Albumin (mg/24 h) & $10.8 \pm 19.2$ & $12.0 \pm 26.4$ & $1.17 \pm 15.42$ & $9.5 \pm 17.2$ & $11.7 \pm 18.8$ & $2.24 \pm 5.88$ \\
\hline Albumin/crea (24 h) & $0.82 \pm 1.40$ & $0.80 \pm 1.36$ & $-0.02 \pm 0.36$ & $0.77 \pm 1.31$ & $0.96 \pm 1.55$ & $0.20 \pm 0.48$ \\
\hline
\end{tabular}

Abbreviations: HK haematocrit, MCHC mean corpuscular/cellular haemoglobin concentration, $M C V$ mean corpuscular/cell volume, CrP C reactive protein, FPG fasting plasma glucose, $\mathrm{HbA1c}$ glycated haemoglobin A1c, $F$ Insulin fasting insulin, HOMA-IR homeostasis model assessment-insulin resistance, Na natrium, $K$ potassium, MG magnesium, Cl chloride, GFR glomerular filtration rate, TC total cholesterol, LDL-C LDL-cholesterol, HDL-C HDL-cholesterol, TG triglycerides, $A S A T$ aspartateaminotranferase, ALAT alanin-aminotranferase, TSH thyroid stimulating hormone, \# $p<0.05$ within the group, \#\# $p<0.01$ within the group, * $p<0.05$ between the

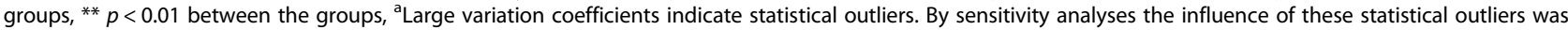
checked. The results in the full analysis set were confirmed

Different authors described that the prevalence of LV diastolic dysfunction measured by diameters of the LA, left ventricle, and LVMI is significantly increased the more components of MetS exist [4, 5, 7].

In the verum group of the present study the diameter of LA was increased and especially related to the HOMA quartiles, but no more than in upper limit of normal. In male but not in female a strong positive correlation between LVMI and LA at baseline as a sign of diastolic dysfunction was demonstrable. In contrary in the placebo group this diameter was reduced. To what extent the SVPBs are relevant in this process is yet unknown. Measured by effect size functional parameters are more improved in the verum group within 6 weeks than structural parameters like LVMI. Overall in literature the findings in disturbances in glucose metabolism and transthoracic echocardiographic evaluated structural and functional parameters are not consistent. This may be based on exclusion of older and patients with higher BMI [46]. In accordance with Rutter et al. [46] and
Hwang et al. [47] we found these relations to different parameters of LV diastolic dysfunction by transthoracic echocardiography. Similar results on LV function in patients with insulin resistance and glycaemic abnormalities were described by Velagaleti et al. [48] by means of MR imaging. These associations were more frequently significant in males. Overall is the reduction of LVMI due to intervention within 6 weeks an interesting finding. The mechanisms of modification of LVMI are not yet fully understood. It is accepted that arterial hypertension is contributing to the development of LV hypertrophy. But the changes in 24-h blood pressure measuring contribute only 25 to $30 \%$ of variation of LV mass [49]. Sundström et al. [50] described in 2000 that different parameters of MetS stronger related to the LV wall thickness and concentric remodelling than to LV hypertrophy.

Later could be shown, that the changes in LVMI are closely related to the insulin resistance in animals as well as humans. In an animal experiment comparable could

Table 6 Changing of patient's characteristics: comparison of Holter ECG before and after dietary intervention

\begin{tabular}{|c|c|c|c|c|c|c|}
\hline & \multicolumn{3}{|c|}{ Verum $(n=29) \times \pm S D$} & \multicolumn{3}{|c|}{ Placebo $(n=25) \times \pm$ SD } \\
\hline & Baseline & Week 6 & Diff & Baseline & Week 6 & Diff \\
\hline VPBs $>500 / 24 h$ & $2486 \pm 2133$ & $2316 \pm 3232$ & $-170 \pm 2469$ & $5717 \pm 7662$ & $2649 \pm 3287$ & $-3068 \pm 5259^{\# \#}$ \\
\hline SV tachycardia (hr > 100/min) & $37.3 \pm 66.1$ & $23.7 \pm 46.0$ & $-13.6 \pm 67.4$ & $52.2 \pm 67.3$ & $39.9 \pm 103.8$ & $-12.4 \pm 96.9$ \\
\hline SVPBs $>200 / 24 h$ & $2000 \pm 1874$ & $2204 \pm 1474$ & $204 \pm 1541$ & $1025 \pm 406$ & $585 \pm 786$ & $-440 \pm 427$ \\
\hline SVPBs $<200 / 24 \mathrm{~h}$ with symptoms & $20.5 \pm 32.9$ & $21.3 \pm 46.9$ & $0.85 \pm 55.83$ & $39.2 \pm 36.4^{*}$ & $107.7 \pm 298.0$ & $68.6 \pm 269.7$ \\
\hline Heart rate (bpm) & $71.4 \pm 12.5$ & $68.4 \pm 10.8$ & $-3.0 \pm 7.9 \#$ & $72.9 \pm 12.7$ & $70.3 \pm 13.2$ & $-2.6 \pm 9.3$ \\
\hline
\end{tabular}

Abbreviations: VPBs ventricular premature beats, SV supraventricular, SVPBs supraventricular premature beats

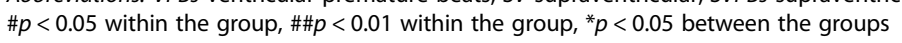


be found the development of structural changes due to insulin resistance in mice within 3 weeks [51]. Verma et al. [52] investigated in 2016 in a subgroup 10 patients with T2DM and performed echo studies at begin and 3 months later. They found a significant reduction in LV mass and an improvement of diastolic function. The mechanism is at all not fully known and needs further elucidation and is not finally to declare at time.

\section{Influence on insulin resistance}

Different compounds and durations of dietary interventions are not comparable in its effects. For this reason the results are not consistent $[14,22]$.

In this study $27.6 \%$ in the verum group and $16.0 \%$ in the placebo group showed an euglycaemic IR measured by HOMA-IR at baseline. That suggests that these changes in glucose metabolism could be found in overweight patients much longer before manifestation of T2DM. At study end we found in verum group a reduction in euglycaemic IR to $10.3 \%$ and in the placebo group to $8.0 \%$. Only in the verum group these parameters of glucose metabolism were reduced after intervention $(p=0.063)$. The significantly increased serum magnesium concentrations in the verum group compared to the placebo group after intervention were only connected with the significantly decrease of HOMA-IR in the verum group. Chutia and Lynrah [53] showed a positive correlation between fasting insulin level and HOMA level in patients with T2DM compared to non-diabetic controls. The correlation between serum magnesium level and fasting insulin level was inversely.

Low vitamin B12 levels have been found in obese adolescents with clinical features of IR [15]. The supplementation of vitamin B12, folate, and coenzyme Q10 in this study was helpful in two ways: on the one hand in general a great part of the population has a deficiency in these micronutrients, especially seniors [54], and on the other hand the substitution may improve the glucose metabolism with a significant decrease in fasting insulin and HOMA-IR. The BMI remained unchanged throughout the study duration of 6 weeks.

The described effects of coenzyme Q10 on glucose metabolism are differently. In an interventional supplementation of coenzyme Q10 in patients with MetS a positive effect on serum insulin levels and HOMA-IR could be found [21]. In contrary Moazen et al. [20] and Azevedo et al. [5] did not verify an effect of coenzyme Q10 on fasting blood glucose and HbA1C level compared to the placebo group. Other investigators [24] found a significant reduction in fasting plasma glucose and HbA1C level but not in serum insulin and HOMA-IR. The effect on lipid profile was not favourable.

\section{Influence on other biochemical parameters}

The most frequently investigated substance is the coenzyme Q10. Supplementations like vitamin C, E, coenzyme Q10 and selenium only in a combination also improved the glucose and lipid metabolism [22]. Folic acid supplementation in patients with T2DM effects a reduction in homocysteine on the other hand it increases glutathione levels with an inverse effect on HbA1C, TG and HDL-C [14].

In accordance with other authors [21, 24] this study did not show a positive influence on lipids (TC, TG, LDL-C) by CoQ10, which was also given in higher dosages.

$\mathrm{CrP}$ was low grade elevated in 20 patients of the verum group and in 16 patients of the placebo group. Even with CrP serum concentrations of $>0.7 \mathrm{mg} / \mathrm{l}$, there is a slightly increased risk [55]. The elevation of $\mathrm{CrP}$ indicates in patients with overweight and obesity as well as with metabolic disorders a higher risk for cardiovascular events. In our study was CrP was slightly reduced after dietary supplementation, and elevated in the placebo group. This effect may be due to magnesium intake by dietary supplementation [11]. After administration of coenzyme Q10, h-CrP was also reduced, according to the findings of Raygan et al. [21], and Shargorodski et al. [22] after intake of $60 \mathrm{mg}$ Q10 combined with other antioxidants like vitamin $\mathrm{C}, \mathrm{E}$ and selenium.

\section{Influence on cardiac arrhythmias}

Magnesium and potassium play an important role in management of CA $[9,12]$. CA are often associated with hypomagnesemia but the pathomechanism of this process is not fully understand because of interaction with other electrolyte disturbances [44]. The hypomagnesemia and hypokalemia are closely linked together by triggering of CA [10]. In this pilot study an effect of the dietary supplementation on VPBs, SVPBs and VAS points could not be shown. The reduction of VPBs in the placebo group may be based on a placebo effect. In the verum group we found a significant reduction in heart rate. This may be caused on slowing of sinus node rate by oral magnesium administration [12]. In this pilot study a correlation between changes in LV function and CA could not be found.

\section{Strength and limitations}

The strength of this study includes a sample of patients with cardiovascular disorders like $\mathrm{AH}, \mathrm{CAD}$, and frequent PBs, and an averaged overweight, which were treated in an Outpatient Practice for Cardiology. Therefore, all were investigated in one centre and all procedures were under same standardized conditions. Limitations were the relative small number of patients and a post-hoc-analysis. In this echocardiographic study we have not measured routinely all parameters of 
diastolic function. Since outliers of several parameters are detected on different patients, a general clean-up of the data appears inappropriate, favouring the use of all available data. The tested parameters must be evaluated with other patient's condition too.

\section{Conclusion}

In this pilot study, dietary intervention with a specific micronutrient combination as add-on to concomitant cardiovascular drug treatment seems to improve cardiometabolic health in patients with CA. The dietary intervention led to a significant decrease in fasting insulin $\geq 58 \mathrm{pmol} / \mathrm{l}(p=0.020)$, and HOMA-IR was reduced in the verum group after 6 weeks $(p=0.053)$. At the same time, parameters of LV diastolic function were improved after intervention in the verum group: significant reduction of LV mass index $(p=0.003)$, and in tendency a decrease of interventricular septal thickness $(p=0.053)$ as well as an increase E/A ratio $(p=0.051)$. The heart rate was significantly decreased $(p=0.027)$, but the effect on reduction of rhythm disturbances like PBs was less pronounced. In both groups serious side effects were not observed. The results of this pilot study give indications for sign of further studies.

\section{Abbreviations}

AH: Arterial hypertension; ALAT: Alanin-aminotransferase; ASAT: Aspartateaminotransferase; BMI: Body-Mass-Index; BP: Blood Pressure; CA: Cardiac arrhythmias; CAD: Coronary artery disease; $\mathrm{Cl}$ : Chloride; $\mathrm{CrP}$ : $\mathrm{C}$ reactive protein; E/A ratio: Ratio of the early (E) to late (A) ventricular filling velocities; ECG: Electrocardiogram; ES: Effect size; F Insulin: Fasting insulin; FPG: Fasting plasma glucose; GFR: Glomerular filtration rate; HbA1c: Glycated haemoglobin A1c; HDL-C: HDL-cholesterol; HK: Haematocrit; HOMAIR: Homeostasis Model Assessment- insulin resistance; IDF: International Diabetes Federation; IGT: Impaired glucose tolerance; IR: Insulin resistance; IVS: Interventricular septum; K: Potassium; LA: Left atrium; LDL-C: LDLcholesterol; LV: Left ventricular; LVEDD: Left ventricular end diastolic diameter; LVEF: Left ventricular ejection fraction; LVESD: Left ventricular end systolic diameter; LVMI: Left ventricular mass index; LVPW: Left ventricular posterior wall; MCHC: Mean corpuscular/cellular haemoglobin concentration; MCV: Mean corpuscular/cell volume; MetS: Metabolic syndrome; Mg: Magnesium; Na: Natrium; PBs: Premature beats; Q1: First Quartile; Q3: Third Quartile; RVEDD: Right ventricular end diastolic diameter; SV: Supraventricular; SVPBs: Supraventricular premature beats; T2DM: Type 2 diabetes mellitus; TC: Total cholesterol; TG: Triglycerides; VPBs: Ventricular premature beats; WC: Waist Circumference; WHtR: Waist-to-Height-Ratio

\section{Acknowledgements}

We would like to acknowledge the team of the Outpatient Practice of Cardiology for their efforts on the conduct of the study.

\section{Funding}

This study was funded by a research contract from Trommsdorff GmbH \& Co. KG, Alsdorf, Germany. The company had no influence on study design, data collection, analysis and interpretation of the results as well as the creation of this paper.

\section{Availability of data and materials}

The datasets used and/or analysed during the current study are available from the corresponding author on reasonable request.

\section{Authors' contributions}

CM designed research, EP conducted the study and prepared the paper, NB conducted the statistical analysis, AW conducted the study, DR monitored the study. EP, CM, NB, AW and DR contributed to the interpretation of the data and the results. CM and DR supported the preparation of the paper. All authors read and approved the final manuscript.

Ethics approval and consent to participate

The study was approved by the Freiburg Ethics Commission International. All patients gave written informed consent to take part in this study.

\section{Consent for publication}

Not applicable.

\section{Competing interests}

The authors declare that they have no competing interests. EP received grants as consultant and as speaker for Trommsdorff.

\section{Publisher's Note}

Springer Nature remains neutral with regard to jurisdictional claims in published maps and institutional affiliations.

\section{Author details}

'Outpatient Practice of Cardiology, Suermondtstr. 13, D-13053 Berlin, Germany. ${ }^{2}$ Medicine and Service Ltd, Department of Biostatistics, Boettcherstr. 10, D-09117 Chemnitz, Germany. ${ }^{3}$ Bonn Education Association for Dietetics r. A, Fuerst-Pueckler-Str. 44, D-50935 Cologne, Germany. ${ }^{4}$ Department of Internal Medicine III, Uniklinik RWTH Aachen, Pauwelsstraße 44, D-52074 Aachen, Germany.

Received: 10 October 2017 Accepted: 14 November 2018

Published online: 03 December 2018

\section{References}

1. Conen D, Adam M, Roche F, Barthelemy J-C, Felber Dietrich D, Imboden M, et al. Premature atrial contractions in the general population: frequency and risk factors. Circulation. 2012;126:2302-8. https://doi.org/10.1161/ CIRCULATIONAHA.112.112300.

2. Massing MW, Simpson RJ Jr, Rautaharju PM, Schreiner PJ, Crow R, Heiss G. Usefulness of ventricular premature complexes to predict coronary heart disease events and mortality (from the atherosclerosis risk in communities cohort). Am J Cardiol. 2006;98:1609-12. https://doi.org/10.1016/j.amjcard. 2006.06.061

3. Ryden L, Grant PJ, Anker SD, Berne C, Cosentino F, Danchin N, et al. ESC guidelines on diabetes, pre-diabetes, and cardiovascular diseases developed in collaboration with the EASD: the task force on diabetes, pre-diabetes, and cardiovascular diseases of the European Society of Cardiology (ESC) and developed in collaboration with the European Association for the Study of diabetes (EASD). Eur Heart J. 2013;34:3035-87. https://doi.org/10. 1093/eurheartj/eht108.

4. Ayalon N, Gopal DM, Mooney DM, Simonetti JS, Grossman JR, Dwivedi A, et al. Preclinical left ventricular diastolic dysfunction in metabolic syndrome. Am J Cardiol. 2014;1 14:838-42. https://doi.org/10.1016/.jamjcard.2014.06.013.

5. Azevedo A, Bettencourt P, Almeida PB, Santos AC, Abreu-Lima C, Hense H$\mathrm{W}$, Barros $\mathrm{H}$. Increasing number of components of the metabolic syndrome and cardiac structural and functional abnormalities-cross-sectional study of the general population. BMC Cardiovasc Disord. 2007;7:17. https://doi. org/10.1186/1471-2261-7-17

6. Galderisi M. Diastolic dysfunction and diabetic cardiomyopathy: evaluation by Doppler echocardiography. J Am Coll Cardiol. 2006;48:1548-51. https:/ doi.org/10.1016/j.jacc.2006.07.033.

7. Ponikowski P, Voors AA, Anker SD, Bueno H, Cleland JGF, Coats AJS, et al. ESC guidelines for the diagnosis and treatment of acute and chronic heart failure: the task force for the diagnosis and treatment of acute and chronic heart failure of the European Society of Cardiology (ESC). Developed with the special contribution of the heart failure association (HFA) of the ESC. Eur J heart fail. 2016. https://doi.org/10.1002/ejhf.592.

8. Bashir Y, Sneddon JF, Staunton HA, Haywood GA, Simpson IA, McKenna WJ, Camm AJ. Effects of long-term oral magnesium chloride replacement in congestive heart failure secondary to coronary artery disease. Am J Cardiol. 1993;72:1156-62.

9. Falco CN, Grupi C, Sosa E, Scanavacca M, Hachul D, Lara S, et al. Successful improvement of frequency and symptoms of premature complexes after oral magnesium administration. Arq Bras Cardiol. 2012;98:480-7. 
10. Geiger H, Wanner C. Magnesium in disease. Clin Kidney J. 2012;5:125-38. https://doi.org/10.1093/ndtplus/sfr165.

11. Song Y, Ridker PM, Manson JE, Cook NR, Buring JE, Liu S. Magnesium intake, C-reactive protein, and the prevalence of metabolic syndrome in middleaged and older U.S. women. Diabetes Care. 2005;28:1438-44.

12. Stühlinger HG. Die Bedeutung von Magnesium bei kardiovaskulären Erkrankungen. J Kardiol. 2002;9:389-95.

13. Aburto NJ, Hanson S, Gutierrez H, Hooper L, Elliott P, Cappuccio FP. Effect of increased potassium intake on cardiovascular risk factors and disease: systematic review and meta-analyses. BMJ. 2013;346:f1378. https://doi.org/ 10.1136/bmj.f1378

14. Child DF, Hudson PR, Jones H, Davies GK, De P, Mukherjee S, et al. The effect of oral folic acid on glutathione, glycaemia and lipids in type 2 diabetes. Diabetes Nutr Metab. 2004;17:95-102.

15. Ho M, Halim JH, Gow ML, El-Haddad N, Marzulli T, Baur LA, et al. Vitamin B12 in obese adolescents with clinical features of insulin resistance. Nutrients. 2014;6:5611-8. https://doi.org/10.3390/nu6125611.

16. Knight BA, Shields BM, Brook A, Hill A, Bhat DS, Hattersley AT, Yajnik CS. Lower circulating B12 is associated with higher obesity and insulin resistance during pregnancy in a non-diabetic white British population. PLoS One. 2015;10:e0135268. https://doi.org/10.1371/journal.pone.0135268.

17. Sazonov V, Maccubbin D, Sisk CM, Canner PL. Effects of niacin on the incidence of new onset diabetes and cardiovascular events in patients with normoglycaemia and impaired fasting glucose. Int J Clin Pract. 2013;67:297302. https://doi.org/10.1111/ijcp.12089.

18. Schwab S, Zierer A, Heier M, Fischer B, Huth C, Baumert J, et al. Intake of vitamin and mineral supplements and longitudinal association with $\mathrm{HbA1c}$ levels in the general non-diabetic population-results from the MONICA/ KORA S3/F3 study. PLoS One. 2015;10:e0139244. https://doi.org/10.1371/ journal.pone.0139244.

19. Sudchada P, Saokaew S, Sridetch S, Incampa S, Jaiyen S, Khaithong W. Effect of folic acid supplementation on plasma total homocysteine levels and glycemic control in patients with type 2 diabetes: a systematic review and meta-analysis. Diabetes Res Clin Pract. 2012;98:151-8. https://doi.org/10. 1016/j.diabres.2012.05.027.

20. Moazen M, Mazloom Z, Ahmadi A, Dabbaghmanesh MH, Roosta S. Effect of coenzyme Q10 on glycaemic control, oxidative stress and adiponectin in type 2 diabetes. J Pak Med Assoc. 2015;65:404-8.

21. Raygan F, Rezavandi Z, Dadkhah Tehrani S, Farrokhian A, Asemi Z. The effects of coenzyme Q10 administration on glucose homeostasis parameters, lipid profiles, biomarkers of inflammation and oxidative stress in patients with metabolic syndrome. Eur J Nutr. 2015. https://doi.org/10.1007/s00394-015-1042-7.

22. Shargorodsky M, Debby O, Matas Z, Zimlichman R. Effect of long-term treatment with antioxidants (vitamin $C$, vitamin $\mathrm{E}$, coenzyme Q10 and selenium) on arterial compliance, humoral factors and inflammatory markers in patients with multiple cardiovascular risk factors. Nutr Metab (Lond). 2010;7:55. https://doi.org/10.1186/1743-7075-7-55.

23. Turk S, Baki A, Solak Y, Kayrak M, Atalay H, Gaipov A, et al. Coenzyme Q10 supplementation and diastolic heart functions in hemodialysis patients: a randomized double-blind placebo-controlled trial. Hemodial Int. 2013;17: 374-81. https://doi.org/10.1111/hdi.12022.

24. Zahedi H, Eghtesadi S, Seifirad S, Rezaee N, Shidfar F, Heydari I, et al. Effects of CoQ10 supplementation on lipid profiles and glycemic control in patients with type 2 diabetes: a randomized, double blind, placebocontrolled trial. J Diabetes Metab Disord. 2014;13:81. https://doi.org/10.1186/ s40200-014-0081-6.

25. Classen HG, Grober U, Kisters K. Drug-induced magnesium deficiency. Med Monatsschr Pharm. 2012;35:274-80.

26. Kaye P. The role of magnesium in the emergency department. Emerg Med J. 2002;19:288-91. https://doi.org/10.1136/emj.19.4.288.

27. Alberti KGM, Zimmet P, Shaw J. The metabolic syndrome-a new worldwide definition. Lancet. 2005;366:1059-62. https://doi.org/10.1016/ S0140-6736(05)67402-8.

28. Schneider HJ, Friedrich N, Klotsche J, Pieper L, Nauck M, John U, et al. The predictive value of different measures of obesity for incident cardiovascular events and mortality. J Clin Endocrinol Metab. 2010;95:1777-85. https://doi. org/10.1210/jc.2009-1584.

29. Browning LM, Hsieh SD, Ashwell M. A systematic review of waist-to-height ratio as a screening tool for the prediction of cardiovascular disease and diabetes: 0.5 could be a suitable global boundary value. Nutr Res Rev. 2010; 23:247-69. https://doi.org/10.1017/50954422410000144.
30. Prineas RJ, Crow RS, Blackburn HW. The Minnesota code manual of electrocardiographic findings: Standards and procedures for measurement and classification. Boston, Mass.: J. Wright; 1982.

31. Lang RM, Badano LP, Mor-Avi V, Afilalo J, Armstrong A, Ernande L, et al. Recommendations for cardiac chamber quantification by echocardiography in adults: an update from the American Society of Echocardiography and the European Association of Cardiovascular Imaging. Eur Heart J Cardiovasc Imaging. 2015;16:233-70. https://doi.org/10.1093/ehjci/jev014.

32. Nagueh SF, Appleton CP, Gillebert TC, Marino PN, Oh JK, Smiseth OA, et al. Recommendations for the evaluation of left ventricular diastolic function by echocardiography. J Am Soc Echocardiogr. 2009;22:107-33. https://doi.org/ 10.1016/j.echo.2008.11.023.

33. Cohen J. Statistical power analysis for the behavioral sciences. 2nd ed. Hillsdale: L. Erlbaum Associates; 1988.

34. Moebus S, Hanisch J, Bramlage P, Losch C, Hauner H, Wasem J, Jockel K-H. Regional differences in the prevalence of the metabolic syndrome in primary care practices in Germany. Dtsch Arztebl Int. 2008;105:207-13. https://doi.org/10.3238/artzebl.2008.0207.

35. von Bibra H, Paulus WJ, St John Sutton M, Leclerque C, Schuster T, Schumm-Draeger P-M. Quantification of diastolic dysfunction via the age dependence of diastolic function - impact of insulin resistance with and without type 2 diabetes. Int J Cardiol. 2015;182:368-74. https://doi.org/10. 1016/j.jicard.2014.12.005.

36. Koliaki C, Roden M. Alterations of mitochondrial function and insulin sensitivity in human obesity and diabetes mellitus. Annu Rev Nutr. 2016;36: 337-67. https://doi.org/10.1146/annurev-nutr-071715-050656.

37. von Bibra H, Paulus W. Diastolische Dysfunktion. Kardiologe. 2016;10:47-55. https://doi.org/10.1007/s12181-015-0035-3.

38. Fontes-Carvalho R, Ladeiras-Lopes R, Bettencourt P, Leite-Moreira A, Azevedo A. Diastolic dysfunction in the diabetic continuum: association with insulin resistance, metabolic syndrome and type 2 diabetes. Cardiovasc Diabetol. 2015;14:4. https://doi.org/10.1186/s12933-014-0168-x.

39. Littarru GP, Tiano L. Clinical aspects of coenzyme Q10: an update. Nutrition. 2010;26:250-4. https://doi.org/10.1016/j.nut.2009.08.008.

40. Quiles JL, Ochoa JJ, Battino M, Gutierrez-Rios P, Nepomuceno EA, Frias ML, et al. Life-long supplementation with a low dosage of coenzyme Q10 in the rat: effects on antioxidant status and DNA damage. Biofactors. 2005;25:7386.

41. Ikee R, Hamasaki Y, Oka M, Maesato K, Mano T, Moriya H, et al. High-density lipoprotein cholesterol and left ventricular mass index in peritoneal dialysis. Perit Dial Int. 2008;28:611-6.

42. Ahn M-S, Kim J-Y, Youn YJ, Kim S-Y, Koh S-B, Lee K, et al. Cardiovascular parameters correlated with metabolic syndrome in a rural community cohort of Korea: the ARIRANG study. J Korean Med Sci. 2010;25:1045-52. https://doi.org/10.3346/jkms.2010.25.7.1045.

43. Ochi A, Ishimura E, Tsujimoto Y, Kakiya R, Tabata T, Mori K, et al. Hair magnesium, but not serum magnesium, is associated with left ventricular wall thickness in hemodialysis patients. Circ J. 2013;77:3029-36.

44. Grober U, Schmidt J, Kisters K. Magnesium in prevention and therapy. Nutrients. 2015;7:8199-226. https://doi.org/10.3390/nu7095388.

45. DiNicolantonio JJ, Bhutani J, McCarty MF, O'Keefe JH. Coenzyme Q10 for the treatment of heart failure: a review of the literature. Open Heart. 2015;2: e000326. https://doi.org/10.1136/openhrt-2015-000326.

46. Rutter MK, Parise H, Benjamin EJ, Levy D, Larson MG, Meigs JB, et al. Impact of glucose intolerance and insulin resistance on cardiac structure and function: sex-related differences in the Framingham heart study. Circulation. 2003;107:448-54.

47. Hwang Y-C, Jee JH, Kang M, Rhee E-J, Sung J, Lee M-K. Metabolic syndrome and insulin resistance are associated with abnormal left ventricular diastolic function and structure independent of blood pressure and fasting plasma glucose level. Int J Cardiol. 2012;159:107-11. https://doi.org/10.1016/j.jijcard. 2011.02.039.

48. Velagaleti RS, Gona P, Chuang ML, Salton CJ, Fox CS, Blease SJ, et al. Relations of insulin resistance and glycemic abnormalities to cardiovascular magnetic resonance measures of cardiac structure and function: the Framingham heart study. Circ Cardiovasc Imaging. 2010;3:257-63. https:// doi.org/10.1161/CIRCIMAGING.109.911438.

49. Majahalme S, Turjanmaa V, Weder A, Lu H, Tuomisto M, Virjo A, Uusitalo A. Blood pressure levels and variability, smoking, and left ventricular structure in normotension and in borderline and mild hypertension. Am J Hypertens. 1996;9:1110-8. 
50. Sundström J, Lind L, Nyström N, Zethelius B, Andrén B, Hales CN, Lithell HO. Left ventricular concentric remodeling rather than left ventricular hypertrophy is related to the insulin resistance syndrome in elderly men. Circulation. 2000;101:2595-600.

51. Zhang L, Jaswal JS, Ussher JR, Sankaralingam S, Wagg C, Zaugg M, Lopaschuk GD. Cardiac insulin-resistance and decreased mitochondrial energy production precede the development of systolic heart failure after pressure-overload hypertrophy. Circ Heart Fail. 2013;6:1039-48. https://doi. org/10.1161/CIRCHEARTFAILURE.112.000228.

52. Verma S, Garg A, Yan AT, Gupta AK, Al-Omran M, Sabongui A, et al. Effect of Empagliflozin on left ventricular mass and diastolic function in individuals with diabetes: an important clue to the EMPA-REG OUTCOME trial? Diabetes Care. 2016;39:e212-3. https://doi.org/10.2337/dc16-1312.

53. Chutia H, Lynrah KG. Association of Serum Magnesium Deficiency with insulin resistance in type 2 diabetes mellitus. J Lab Physicians. 2015;7:75-8. https://doi.org/10.4103/0974-2727.163131.

54. DGE. Referenzwerte für die Nährstoffzufuhr. 2nd ed. Neustadt an der Weinstrasse: Neuer Umschau Buchverlag; 2015.

55. Ridker PM. High-sensitivity C-reactive protein: potential adjunct for global risk assessment in the primary prevention of cardiovascular disease. Circulation. 2001;103:1813-8.

Ready to submit your research? Choose BMC and benefit from:

- fast, convenient online submission

- thorough peer review by experienced researchers in your field

- rapid publication on acceptance

- support for research data, including large and complex data types

- gold Open Access which fosters wider collaboration and increased citations

- maximum visibility for your research: over $100 \mathrm{M}$ website views per year

At $\mathrm{BMC}$, research is always in progress.

Learn more biomedcentral.com/submissions 